\title{
Impact of age, gender, profession and marital status on 3D facial perception
}

\author{
Anas A. Al Omari ${ }^{1}$, Khaled H. Attia ${ }^{2}$, Faten H. Eid ${ }^{3}$, Mostafa M. El-Dawlatly ${ }^{4}$ and Yehya A. Mostafa ${ }^{5 *}$ \\ ${ }^{1}$ Resident, Department of Orthodontics and Dentofacial Orthopedics, Faculty of Dentistry, Cairo University, Cairo, Egypt \\ ${ }^{2}$ Professor, Department of Orthodontics and Dentofacial Orthopedics, Faculty of Dentistry, Cairo University, Cairo, Egypt \\ ${ }^{3}$ Professor of Orthodontics, Department of Orthodontics and Dentofacial Orthopedics, Faculty of Oral and Dental Medicine, Cairo University, Cairo, Egypt \\ ${ }^{4}$ Lecturer, Department of Orthodontics and Dentofacial Orthopedics, Faculty of Oral and Dental Medicine, Cairo University, Cairo, Egypt \\ ${ }^{5}$ Professor and Head of the Department of Orthodontics and Dentofacial Orthopedics, Faculty of Oral and Dental Medicine, Future University, Cairo, Egypt
}

\begin{abstract}
Objectives: The aim of the study is to evaluate the impact of occupation, age, gender, and marital status of raters on the perception of 3D facial images (PFI). Setting and sample population: Thirty subjects were selected.

Material and methods: 3dMDface system and software was used for a 3D stereophotogrammetrical image capturing of these subjects. From these 3D images, 5 different facial views were obtained for every subject; Full Frontal (FF), Full Profile (FP), Lower Frontal (LF), Lower Profile (LP), and Dynamic (D) views. The panel of raters consisted of 20 orthodontists, 50 dentists, and 100 laypersons with equal number of males and females. A hundred and nine of the raters were single and 61 were married. The raters made their scoring on a scale from A to $\mathrm{E}$ (Most attractive to Least attractive, respectively). The collected data were statistically analyzed.
\end{abstract}

Results: The occupation, age, and marital status of raters played no role in the perception of 3D facial images. Female raters gave significantly higher mean score than male raters in their perception of female images, while no significant difference was found for male images. Dynamic view and Lower Frontal view were the most preferred views for female and male images, respectively. Full frontal view was the least preferred view for both female and male images.

Conclusion: 3D Full frontal view in the perception of 3D facial images is not reliable. A realistic 3 dimensional vision of the entire face should be considered as a most robust and reliable diagnostic tool.

\section{Introduction}

For a long established period of time, since the introduction of the Broadbent cephalometry [1], the diagnostic methods in orthodontics had used the two-dimensional (2D) representations of patients' craniofacial morphology. These $2 \mathrm{D}$ diagnostic methods spot the main focus solely on hard tissue information. Nowadays, the paradigm of our treatment goals has shifted with more emphasis on soft tissue parameters [2]. This emphasis on soft tissue required a similar shift to novel approaches for 3D imaging.

There have been many techniques for 3D facial imaging including laser scanning [3], computerized tomography [4], stereolithography [5], and ultrasonograhy [6]. Most of these techniques require the use of prohibitively expensive equipment and highly skilled technical support. These techniques carried considerable risks for the patient, such as exposing the body to high doses of radiation, and the eyes to laser light [7]. Stereophotographic 3D technology introduced by *3dMDface system was claimed to be rapid, safe, and easy to operate. To date, no studies have been conducted to evaluate the variation in raters' perception of these $3 \mathrm{D}$ facial images.

The aim of this study was to explore the effect of raters' attributes (occupation, age, gender, and marital status) on the perception of $3 \mathrm{D}$ facial images (PFI).

\section{Material and methods}

Thirty subjects ( 15 males and 15 females) were selected, out of 100 , to satisfy the following inclusion criteria: adults, same ethnic group (Caucasian), having a normal occlusion, having no history of previous orthodontic treatment and free of developmental anomalies or related syndromes. All the subjects were informed that their photographs were going to be used for research purpose and were asked to sign a written consent form.

The panel of raters was a total of 170 and comprised 20 orthodontists (age range 25-55 years), 50 dentists (age range 25-46 years), and 100 laypersons (age range 20-65 years). There were equal number of males and females on each panel to eliminate sex bias. Of the 170 raters, 109 of raters were single and 61 were married.

Image capturing: To capture the images, each subject was seated in a natural head position by looking forward as if he/she is looking at his/

Correspondence to: Yehya A. Mostafa, Head and Professor, Department of Orthodontics and Dentofacial Orthopedics, Faculty of Oral and Dental Medicine, Future University, Cairo, Egypt, Tel: 002-012-213-1934, Fax: 333471037, E-mail: mangoury@usa.net

Received: November 25, 2016; Accepted: December 20, 2016; Published: December 23, 2016 
her eyes in a mirror with the lips closed at rest and with standardized 1.524 meter (five feet) object-to-lens distance. For the digital 3D image acquisition, a 3D stereophotogrammetrical camera and a software program modular system ${ }^{*}$ were used. The $3 \mathrm{dMDface}$ system consists of 6

\section{*3dMDface System (version 1.0)}

medical-grades, machine-vision cameras on 2 pods; each contains 1 full color and 2 black-and-white cameras. Both pods were connected to a computer with a fire wire cable. The pictures were captured by light photography.

The cameras were synchronized to image each subject in $1.5 \mathrm{~ms}$ with high resolution, enabling geometry to be processed as one continuous point cloud; single raw data was set with one coordinate system (no stitching), this provided ear-to-ear coverage. The images obtained from those 6 cameras were reconstructed into a 3D stereophotogrammetrical image. The digital 3D images could be viewed using a software program $^{* *}$.

Views construction: The subjects were presented in five different views:

1) Dynamic (D) View: represented as a video which allows the subject's face to rotate to the right by 90 degrees and to the left by 90 degrees in a dynamic motion (Figures 1 and 2).

2) Full Frontal (FF) View: during rotation of the dynamic view, an image at a standardized position was captured for each subject to obtain the conventional frontal view (Figures 3 and 4).

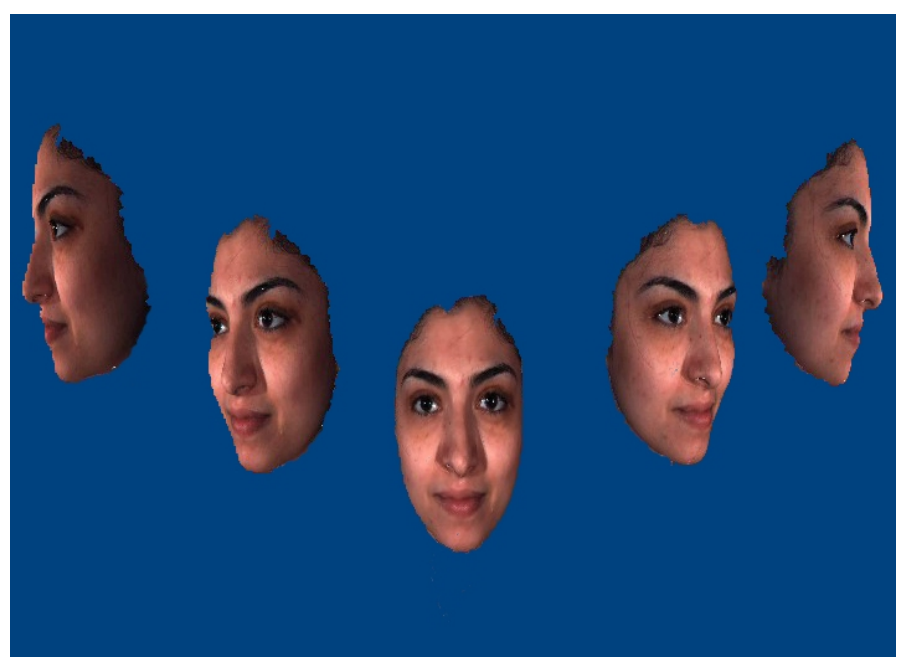

Figure 1. Dynamic view of a Female subject.

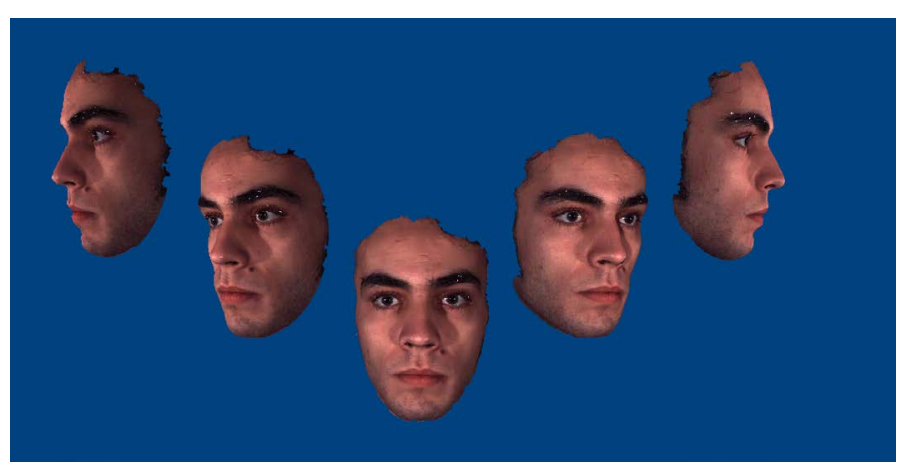

Figure 2. Dynamic view of a Male subject.
3) Full Profile (FP) View: during rotation of the dynamic view, an image at a

**3dMDpatient software program (version 1.0)

standardized position was captured for each subject to obtain the conventional profile view showing the head anterior to the ear, $<2 \mathrm{~mm}$ of opposite eyebrow or eyelash was visible, one philtral column visible, and the lips were closed (Figures 5 and 6).

4) Lower Frontal (LF) View: obtained from cropping the FF view. The view extended soft tissue subnasale superiorly to soft tissue menton inferiorly and a horizontal line perpendicular to the subnasale line at the angle of the mandible (Figures 7 and 8 ).

5) Lower Profile (LP) View: obtained from cropping the FP view. The view extended vertically from soft tissue" subnasale" superiorly to soft tissue "menton" inferiorly and horizontally from a point anterior to the tip of the nose to a point posterior to the angle of the mandible (Figures 9 and 10).

Rating of photographs: The sets of views were copied to 5 slide shows in a PowerPoint $t^{* * *}$ presentation form for projection on a portable desktop showing screen, one slide for each view, separately. The raters

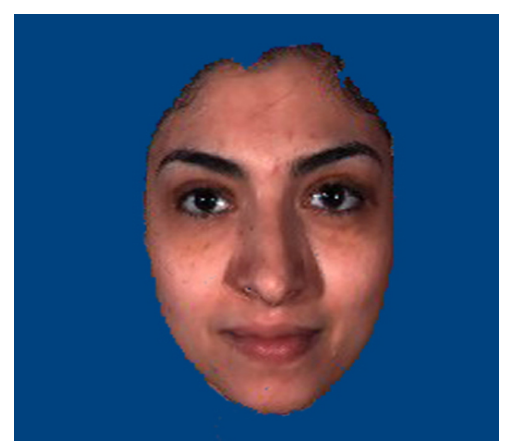

Figure 3. Full Frontal view of a Female subject.

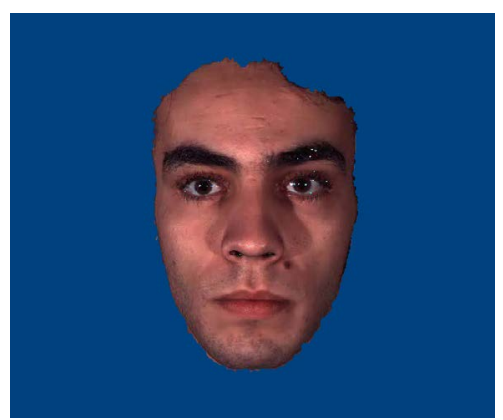

Figure 4. Full Frontal view of a Male subject.

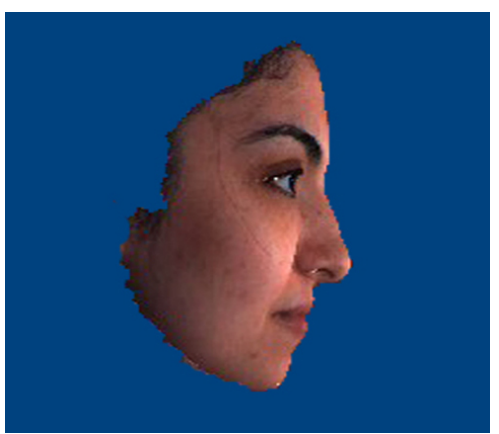

Figure 5. Full Profile view of a Female subject. 


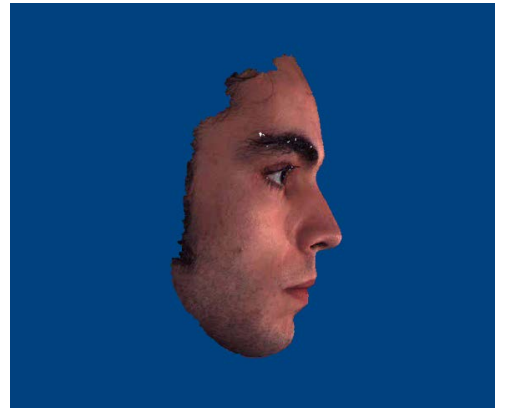

Figure 6. Full Profile view of a Male subject.

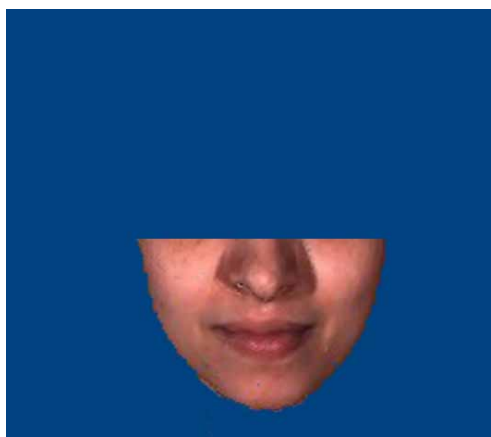

Figure 7. Lower Frontal view of a Female subject.

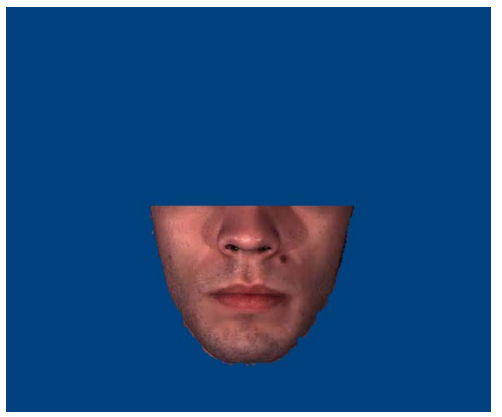

Figure 8. Lower Frontal view of a Male subject.

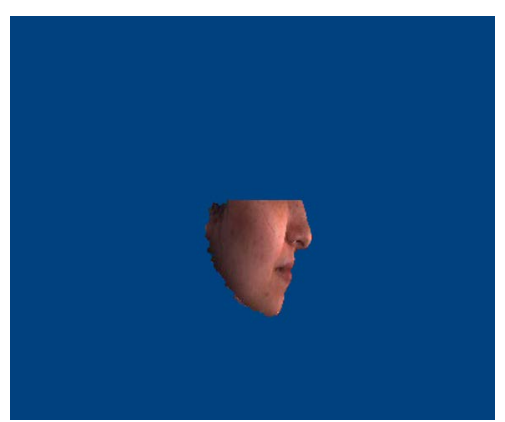

Figure 9. Lower Profile view of a Female subject.

were told that they would see 5 slide; each would show one view for 30 subjects ( 15 females and 15 males). Raters were unaware that the five different slides were comprising the same subjects to eliminate the interrelation of the views.

The instructions for the raters before they examined the images of each view were as follows:

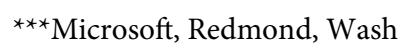

"Images of subjects will be presented to you sequentially. The task is to rate each image on a scale from $\mathrm{A}$ to $\mathrm{E}$ ( $\mathrm{A}$ is the most attractive and $\mathrm{E}$ is the least attractive). We solicit your personal opinion; there is no "right answer". The time required to rate each image should not exceed 5-6 seconds. Be aware that when two or more subjects appear equally matched, small differences in their ratings will not affect the experimental outcome."

After the raters had an opportunity to practice with the computer, an additional image of each view, not included in the sample, was placed on the first slide, so that they could familiarize themselves with the rating procedure. Each rater would receive the images while seating with unobstructed views of the screen and close enough to allow for detailed examination. Each rater made his or her evaluation privately and they were asked not to return to any previously viewed images as they proceeded through the binder. Each image was displayed for 5-6 seconds to take the first impression evaluation.

Statistical analysis: Assessment of various views was calculated, normalized and tabulated on a continuous scale from 0 to 100 for each of the females' and males' views separately. Statistical analysis was carried out using ANOVA (Analysis of Variance) for comparing the perception of orthodontists, dentists and laypersons. Correlation.

Analysis (Pearson's Correlation Coefficient) was used for evaluating the role of raters' age in the perception of different views, and Independent Samples Test (T-test for Equality of Means) was used to find out the effect of gender and marital status of raters on the perception.

\section{Results}

For clarity, the results will be presented to answer the followings questions:

Question I: Is there a difference between laypersons, dentists and orthodontists in their perception of facial images (PFI)?

By comparing the perception of facial images of orthodontists, dentists, and laypersons, the results showed no significant difference in their rating of the five facial views of female and male images (Figures 11 and 12) (Tables 1 and 2).

\section{Question II: Does the rater age play a role in PFI?}

The results of PCC revealed no correlation between age of raters and mean scores of the five facial views of the female and male images (Tables 3 and 4).

Question III: Is there a difference between the rater genders in the PFI?

The study of this variable was conducted using Independent Samples Test. It showed higher mean scores for female raters than

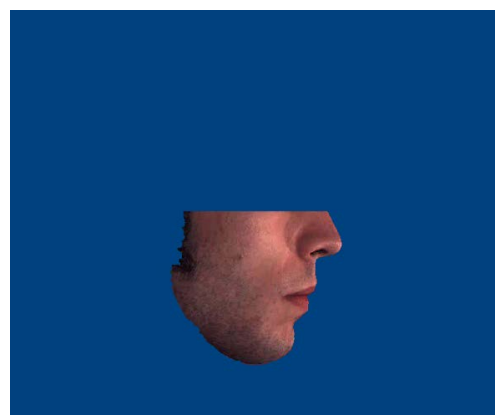

Figure 10. Lower Profile view of a Male subject. 


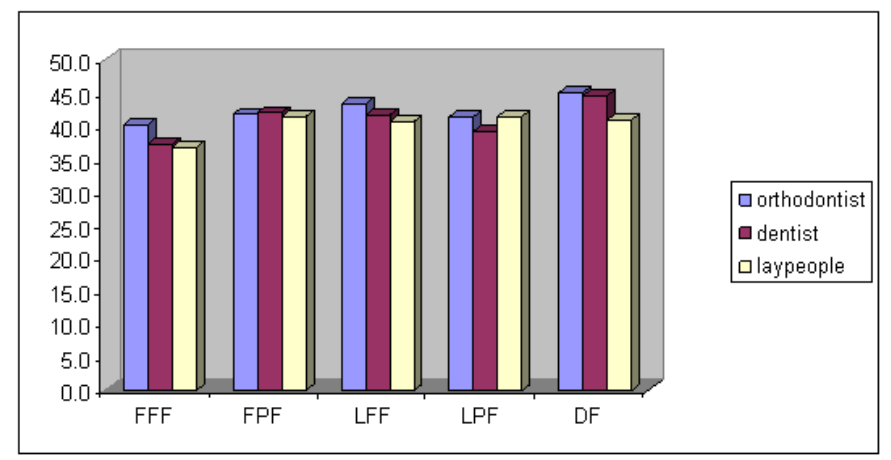

Figure 11. Bar chart of the difference in perception of different female views among different occupations.

Table 1. Difference in mean scores of females views according to raters occupation.

\begin{tabular}{|c|c|c|c|c|}
\hline \multirow{2}{*}{ Views } & Orthodontist & Dentist & laypersons & \multirow{2}{*}{$\boldsymbol{P}$-value } \\
\cline { 2 - 4 } & $\mathbf{M S} \pm \mathbf{S E}$ & $\mathbf{M S} \pm \mathbf{S E}$ & $\mathbf{M S} \pm \mathbf{S E}$ & \\
\hline FF & $40.1 \pm 2.49$ & $37.2 \pm 1.94$ & $36.8 \pm 1.56$ & 0.65 \\
\hline FP & $41.7 \pm 2.66$ & $41.9 \pm 2.06$ & $41.4 \pm 1.70$ & 0.98 \\
\hline LF & $43.2 \pm 2.94$ & $41.6 \pm 2.11$ & $40.7 \pm 1.63$ & 0.80 \\
\hline LP & $41.3 \pm 2.60$ & $39.1 \pm 2.10$ & $41.3 \pm 1.79$ & 0.72 \\
\hline D & $45.0 \pm 2.64$ & $44.4 \pm 2.14$ & $40.9 \pm 1.63$ & 0.30 \\
\hline
\end{tabular}

MS : Mean Scores SE: Standard Error

$\mathrm{p}>0.05$ Non significant

Table 2. Difference in mean scores of male views according to raters occupation.

\begin{tabular}{|c|c|c|c|c|}
\hline \multirow{2}{*}{ Views } & Orthodontist & Dentist & laypersons & \multirow{2}{*}{$\boldsymbol{P}$-value } \\
\cline { 2 - 4 } & $\mathbf{M S} \pm \mathbf{S E}$ & $\mathbf{M S} \pm \mathbf{S E}$ & $\mathbf{M S} \pm \mathbf{S E}$ & \\
\hline FF & $34.1 \pm 2.99$ & $36.4 \pm 1.68$ & $37.4 \pm 1.74$ & 0.67 \\
\hline FP & $39.1 \pm 3.13$ & $43.4 \pm 1.80$ & $40.6 \pm 1.74$ & 0.47 \\
\hline LF & $42.6 \pm 2.86$ & $45.7 \pm 1.97$ & $46.5 \pm 1.86$ & 0.64 \\
\hline LP & $42.3 \pm 2.86$ & $44.5 \pm 1.80$ & $44.8 \pm 1.97$ & 0.84 \\
\hline D & $39.4 \pm 3.23$ & $39.8 \pm 1.87$ & $38.5 \pm 1.82$ & 0.89 \\
\hline
\end{tabular}

MS : Mean Scores SE: Standard Error

$\mathrm{p}>0.05$ Non significant

Table 3. Correlation of female views with raters age.

\begin{tabular}{|c|c|c|}
\hline Views & R & P Value \\
\hline FF & -0.052 & 0.504 \\
\hline FP & -0.032 & 0.682 \\
\hline LF & -0.050 & 0.519 \\
\hline LP & -0.050 & 0.520 \\
\hline D & -0.050 & 0.516 \\
\hline
\end{tabular}

$P>0.05$ Non Significant

Table 4. Correlation of male views with raters age.

\begin{tabular}{|c|c|c|}
\hline Views & R & P Value \\
\hline FF & -0.025 & 0.751 \\
\hline FP & -0.093 & 0.226 \\
\hline LF & -0.066 & 0.391 \\
\hline LP & -0.058 & 0.451 \\
\hline D & -0.005 & 0.947 \\
\hline
\end{tabular}

$\mathrm{P}>0.05$ Non Significant

male raters regarding the five views of female images with a very high significant difference for $\mathrm{D}, \mathrm{FF}$, and LF views and high significant difference for FP, and LP views (Table 5).

On the other hand, there was no significant difference between the mean scores of female and male raters concerning all views of male images (Table 6) (Figures 13 and 14).

\section{PFI? \\ Question IV: Does the marital status of the rater play a role in}

Independent Samples Test revealed no significant difference between single and married raters in their evaluation of the five views of female and male images (Tables 7 and 8) \& (Figures 15 and 16). There was only significant difference in the LP view of the female subjects,

Table 5. Difference in mean scores of females views according to raters gender.

\begin{tabular}{|c|c|c|c|}
\hline View & Female & Male & $\boldsymbol{P}$-value \\
\hline & $\mathbf{M S} \pm \mathbf{S E}$ & $\mathbf{M S} \pm \mathbf{S E}$ & \\
\hline FF & $41.4 \pm 1.41$ & $33.2 \pm 1.62$ & $0.00018^{* * *}$ \\
\hline FP & $45.2 \pm 1.63$ & $38.0 \pm 1.68$ & $0.00230^{* *}$ \\
\hline $\mathbf{L F}$ & $45.5 \pm 1.55$ & $37.0 \pm 1.69$ & $0.00029^{* * *}$ \\
\hline $\mathbf{L P}$ & $44.5 \pm 1.73$ & $36.9 \pm 1.73$ & $0.00224^{* *}$ \\
\hline $\mathbf{D}$ & $46.7 \pm 1.63$ & $38.1 \pm 1.61$ & $0.00022^{* * *}$ \\
\hline
\end{tabular}

MS: Mean Scores

$* * \mathrm{P}<0.01$ Highly Significant

$* * * \mathrm{P}<0.001$ Very Highly Significant

Table 6. Difference in mean scores of males views according to raters gender.

\begin{tabular}{|c|c|c|c|}
\hline View & Female & Male & P -value \\
\hline & MS \pm SE & MS \pm SE & \\
\hline FF & $36.9 \pm 1.66$ & $36.6 \pm 1.72$ & 0.90197 \\
\hline FP & $42.7 \pm 1.61$ & $39.8 \pm 1.80$ & 0.22837 \\
\hline LF & $46.9 \pm 1.80$ & $44.6 \pm 1.82$ & 0.37558 \\
\hline LP & $46.7 \pm 1.92$ & $42.2 \pm 1.77$ & 0.08980 \\
\hline D & $38.7 \pm 1.86$ & $39.3 \pm 1.71$ & 0.82211 \\
\hline
\end{tabular}

MS: Mean Scores

$* * \mathrm{P}<0.01$ Highly Significant

$* * * \mathrm{P}<0.001$ Very Highly Significant

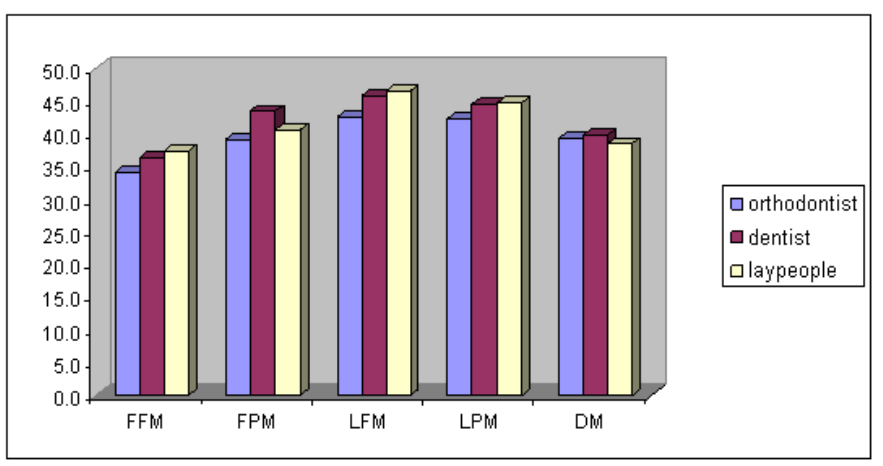

Figure 12. Bar chart of the difference in perception of different male views among different occupations.

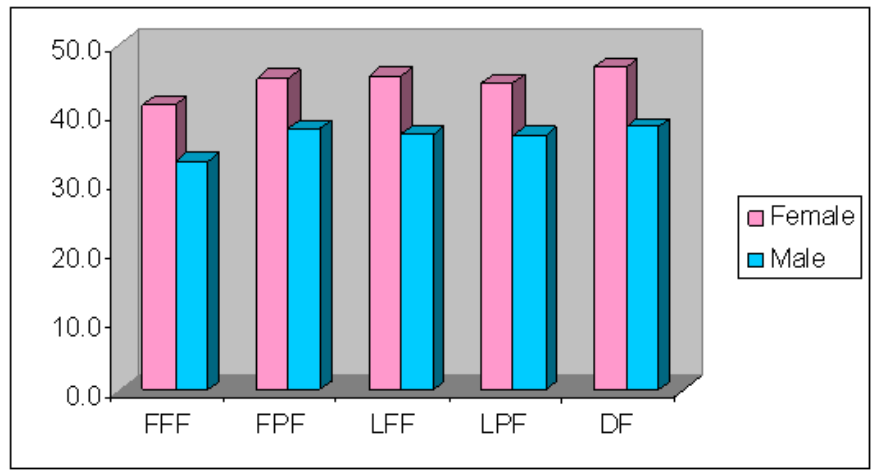

Figure 13. Bar chart showing the effect of raters gender on female views. 


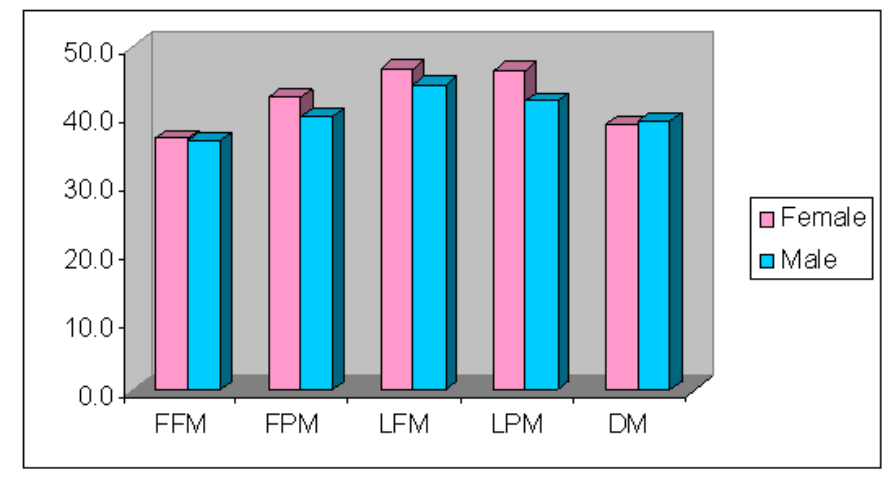

Figure 14. Bar chart showing the effect of raters gender on Male views.

Table 7. Difference in mean scores of females views according to raters marital Status.

\begin{tabular}{|c|c|c|c|}
\hline View & Single & Married & $\boldsymbol{P}$-value \\
\hline & MS \pm SE & MS \pm SE & \\
\hline FF & $38.4 \pm 1.32$ & $35.3 \pm 2.02$ & 0.18892 \\
\hline FP & $42.9 \pm 1.39$ & $39.3 \pm 2.23$ & 0.14853 \\
\hline LF & $42.7 \pm 1.40$ & $38.6 \pm 2.14$ & 0.09577 \\
\hline LP & $42.7 \pm 1.47$ & $37.0 \pm 2.24$ & 0.02872 \\
\hline D & $43.9 \pm 1.48$ & $39.7 \pm 1.98$ & 0.09253 \\
\hline
\end{tabular}

MS: Mean Scores

$* * \mathrm{P}<0.01$ Highly Significant

$* * * \mathrm{P}<0.001$ Very Highly Significant

Table 8. Difference in mean scores of males views according to raters marital status.

\begin{tabular}{|c|c|c|c|}
\hline View & Single & Married & P -value \\
\hline & MS \pm SE & MS \pm SE & \\
\hline FF & $37.9 \pm 1.39$ & $34.6 \pm 2.18$ & 0.19332 \\
\hline FP & $42.7 \pm 1.43$ & $38.8 \pm 2.19$ & 0.12338 \\
\hline LF & $47.1 \pm 1.55$ & $43.4 \pm 2.24$ & 0.16041 \\
\hline LP & $45.5 \pm 1.55$ & $42.5 \pm 2.39$ & 0.27289 \\
\hline D & $39.5 \pm 1.56$ & $38.0 \pm 2.15$ & 0.56002 \\
\hline
\end{tabular}

MS: Mean Scores

$* * \mathrm{P}<0.01$ Highly Significant

$* * * \mathrm{P}<0.001$ Very Highly Significant

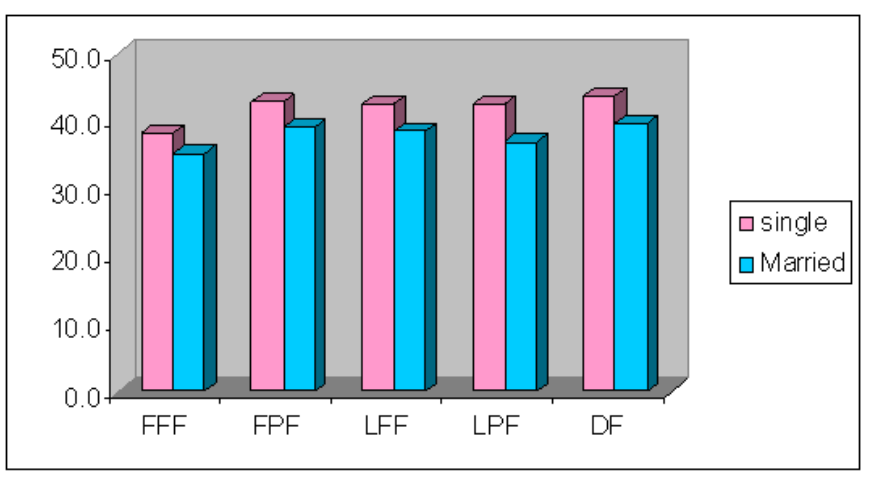

Figure 15. Bar chart showing the effect of raters marital status on female views.

where the single rater gave higher mean scores than married raters.

\section{Question V: Which of the views affects the PFI?}

Descriptive statistics for the scores of the different views was carried out. According to these results, the highest mean score for the female images was given to the Dynamic view followed by the Full Profile view (mean score 42.4 and 41.6 respectively) whereas, the Full Frontal view was the least scored (mean score 37.3) (Table 9).

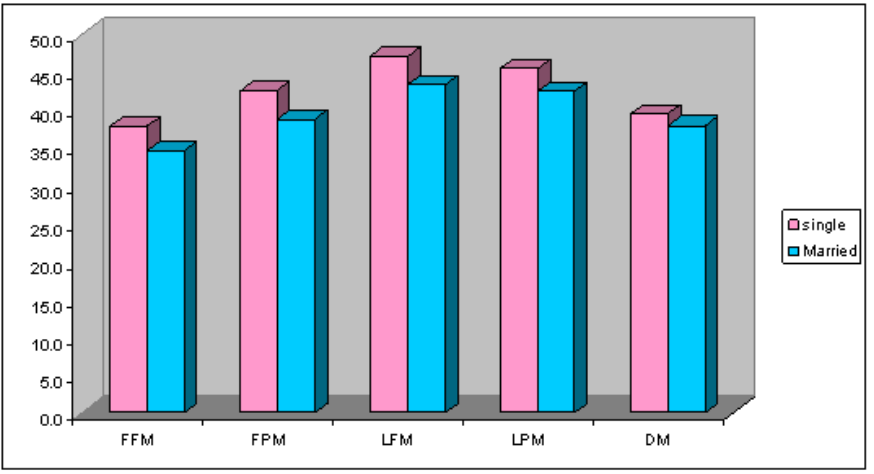

Figure 16. Bar chart showing the effect of raters marital status on male views.

Table 9. Descriptive Statistics of female views.

\begin{tabular}{|c|c|c|c|c|}
\hline Views & Number & MS \pm SE & Lower Bound & Upper Bound \\
\hline FF & 170 & $37.3 \pm 1.12$ & 35.1 & 39.5 \\
\hline FP & 170 & $41.6 \pm 1.20$ & 39.2 & 43.9 \\
\hline LF & 170 & $41.2 \pm 1.19$ & 38.9 & 43.6 \\
\hline LP & 170 & $40.7 \pm 1.25$ & 38.2 & 43.2 \\
\hline D & 170 & $42.2 \pm 1.19$ & 40.1 & 44.7 \\
\hline
\end{tabular}

MS : Mean Scores SE: Standard Error

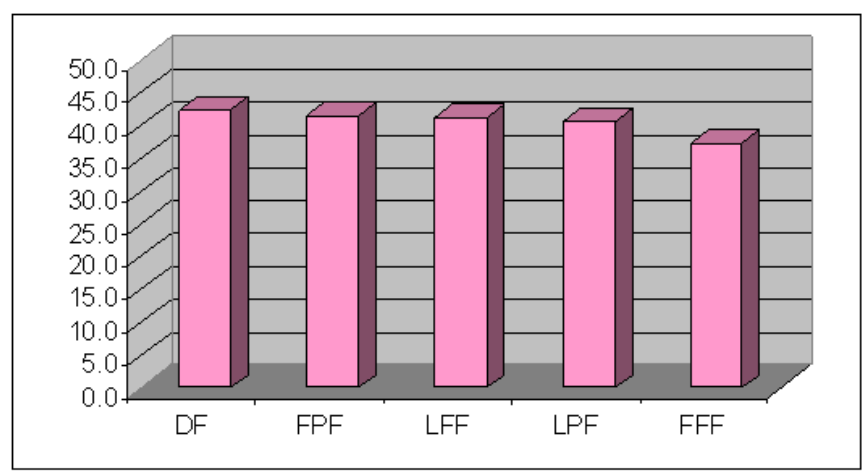

Figure 17. Bar chart of the ranking of attractiveness for female views according to the mean score.

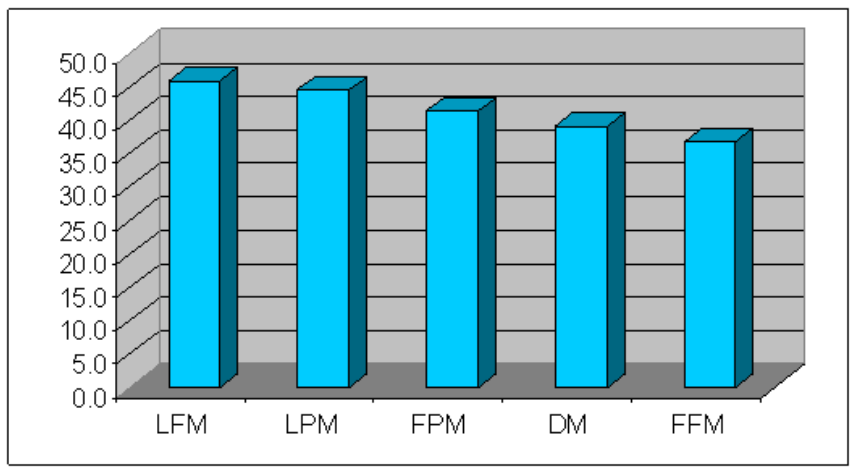

Figure 18. Bar chart of the ranking of attractiveness for male Views according to the mean score.

For male images, the highest mean score was given to the Lower frontal view followed by Lower Profile view (mean score 45.8 and 44.4 respectively). Similar to female images, the least scored view was the Full Frontal view (mean score 36.7) (Table 10) (Figures 17 and 18).

Multiple comparisons (Least Significant Difference test) were done to find out the correlation between the different facial views of female 
and male images separately and the degree of significance between the views (Tables 11 and 12).

\section{Discussion}

The past two decades have witnessed advances in computer hardand software tools that allowed for improvements in 3D hard and soft tissue imaging. Three-dimensional capturing tools have been developed and were reported to be applicable in orthodontics $[8,9]$. Ferrario, et al. [10] analyzed the facial soft tissues 3-dimensionally using mesh diagrams and CCD cameras, while Oliveira, et al. [11] evaluated the changes in the maxilla before and after orthodontic treatment using a 3D laser scanner. Han, et al. [12] introduced facial soft-tissue analysis using $3 \mathrm{D}$ computed tomography. These three-dimensional techniques, however, have some drawbacks $[13,14]$.

In this study, stereophotogrammetry introduced by $3 \mathrm{dMD}$ face system was used to obtain the $3 \mathrm{D}$ facial images. The process of imaging was more simple and took less time than traditional photography.

Table 10. Descriptive Statistics of male view.

\begin{tabular}{|c|c|c|c|c|}
\hline Views & Number & MS \pm SE & Lower Bound & Upper Bound \\
\hline FF & 170 & $36.7 \pm 1.19$ & 34.4 & 39.1 \\
\hline FP & 170 & $41.3 \pm 1.21$ & 38.9 & 43.7 \\
\hline LF & 170 & $45.8 \pm 1.28$ & 43.2 & 48.3 \\
\hline LP & 170 & $44.4 \pm 1.31$ & 41.9 & 47.0 \\
\hline D & 170 & $39.0 \pm 1.26$ & 36.5 & 41.5 \\
\hline
\end{tabular}

MS : Mean Scores

SE: Standard Error

Table 11. Multiple comparisons of female views "Least Significant Difference (LSD)".

\begin{tabular}{|c|c|c|c|c|}
\hline View Vs. View & & Mean Difference & \pm SE & P-value \\
\hline FF & FP & -4.31 & 1.68 & $0.01053^{*}$ \\
\hline FF & LF & -3.96 & 1.68 & $0.01880^{*}$ \\
\hline FF & LP & -3.41 & 1.68 & $0.04290^{*}$ \\
\hline FF & D & -5.14 & 1.68 & $0.00233^{* *}$ \\
\hline FP & LF & 0.35 & 1.68 & 0.83390 \\
\hline FP & LP & 0.90 & 1.68 & 0.59206 \\
\hline FP & D & -0.82 & 1.68 & 0.62465 \\
\hline LF & LP & 0.55 & 1.68 & 0.74428 \\
\hline LF & D & -1.18 & 1.68 & 0.48461 \\
\hline LP & D & -1.73 & 1.68 & 0.30541 \\
\hline
\end{tabular}

SE: Standard Error

$P>0.05$ Non Significant

$* \mathrm{P}<0.05$ Significant

$* * \mathrm{P}<0.01$ Highly Significant

Table 12. Multiple comparisons of male views "Least Significant Difference (LSD)".

\begin{tabular}{|c|c|c|c|c|}
\hline View Vs. View & & Mean Difference & \pm SE & P-value \\
\hline FF & FP & -4.55 & 1.77 & $0.01027^{*}$ \\
\hline FF & LF & -9.05 & 1.77 & $0.00000^{* * *}$ \\
\hline FF & LP & -7.73 & 1.77 & $0.00001^{* * *}$ \\
\hline FF & D & -2.27 & 1.77 & 0.19875 \\
\hline FP & LF & -4.50 & 1.77 & $0.01112^{*}$ \\
\hline FP & LP & -3.18 & 1.77 & 0.07283 \\
\hline FP & D & 2.27 & 1.77 & 0.19875 \\
\hline LF & LP & 1.32 & 1.77 & 0.45443 \\
\hline LF & D & 6.77 & 1.77 & $0.00014^{* * *}$ \\
\hline LP & D & 5.45 & 1.77 & $0.00212^{* *}$ \\
\hline
\end{tabular}

SE: Standard Error

$P>0.05$ Non Significant

$* \mathrm{P}<0.05$ Significant

$* * \mathrm{P}<0.01$ Highly Significant

$* * * \mathrm{P}<0.001$ Very Highly Significant
Additionally, from a single 3D data set, any 2D photographic view could be generated (left and right laterals, frontal, left and right oblique) [15].

Perception of these 3D facial images (PFI) may be related to the occupation, gender, age, and marital status of the raters. The aim of this study was to evaluate the effect of these variables on the PFI. There was a considerable controversy in the literature as to whether laypersons and professionals, including orthodontists and dentists, agreed in their perception of facial images. Ackerman and Proffit [16] noted that the orthodontist's view of facial images and that of the patient [or parent] may differ considerably. Several studies reported an agreement between professionals and laypersons [16-24], while others reported significant disagreements [25-32]. In this study, a good agreement was found between orthodontists, dentists and laypersons in their rating of different images in the different views.

Similarly, conflicting results exist in literature regarding the relationship between the rater gender and their PFI. It was reported that gender had no effect on perception $[21,31,33]$ but other studies reported difference between males and females in their PFI [25,27,29,34-38]. In this study, significant differences were found where female raters gave higher scores to female images. No significant difference was found between genders in rating male images.

Regarding the age effect, the fact that the raters were all adults may explain the lack of influence found in this study. Kokich, et al. [39] found that age has no effect on perception of dental images and is in contrast with other studies that found that age can affect the PFI $[25,35]$.

Little or no data was found in the orthodontic literature regarding the effect of marital status of the raters on the PFI. The results of this study showed no significant difference between single and married raters in their rating of female and male images in all views except for LP view of the female images, where the single rater gave higher mean scores than married raters.

When different facial views were considered, the most preferred view for female images was the Dynamic view followed by Full Profile view while for male images, the most preferred view was the Lower frontal view followed by Lower Profile view. An agreement was found for both female and male images in the least preferred view which was the full frontal view. This indicates that we should not rely only on 3D full frontal view in the PFI; we would rather have a realistic 3 dimensional vision at the entire face. This result is in contrast with another study which reported that frontal views were rated as more attractive than profile views [32]. It should be noted, however, that this study was carried out on a 2 dimensional basis.

Previous studies comparing the difference in PFI of raters with different variables were using 2 dimensional images. This study is the first to utilize 3 dimensional images in the evaluation of facial perception.

\section{Conclusion}

Proper evaluation of facial esthetics requires a holistic approach, combining several views. Despite the diversity of raters' attributes, a trend in esthetic preference was focused.

\section{Authors contribution}

Anas A. Al Omari: Gathering the data for the research, performing the designated measurements, interpretation of the results, writing the manuscript. 
Khaled H. Attia: Gathering the data for the research, performing the designated measurements, interpretation of the results, writing the manuscript.

Faten H. Eid: Performing the designated measurements, interpretation of the results, revising the written manuscript.

Mostafa M. El-Dawlatly: Contributing in the assessment process and revising the manuscript.

Yehya A. Mostafa: Developing the research idea, supervising the stage of data gathering, supervising the performance of the measurements, interpretation of the results, revision of the manuscript.

\section{References}

1. Broadbent BH (1931) A new x-ray technique and its application to orthodontia. Angle Orthod 1: 45-66.

2. Proffit WR (2003) Contemporary treatment of dentofacial deformity. St Louis, Mo: Mosby; 92-95.

3. McCance AM, Moss JP, Wright WR, Linney AD, James DR (1992) A three dimensional soft tissue analysis of 16 skeletal Class II patients following bimaxillary osteotomy. $\mathrm{Br}$ J Oral MaxillofacSurg 30: 221-232.

4. Moss JP, Grindrod SR, Linney AD, Arridge SR, James D (1988) A computer system for the interactive planning and prediction of maxillofacial surgery. Am J Orthod Dentofacial Orthop 94: 469-475. [Crossref]

5. Bill JS, Reuther JF, Dittmann W, Kübler N, Meier JL, et al. (1995) Stereolithography in oral and maxillofacial operation planning. Int J Oral Maxillofac Surg 24: 98-103. [Crossref]

6. Hell B (1995) 3D sonography. Int J Oral Maxillofac Surg 24: 84-89. [Crossref]

7. Ayoub AF, David L (1996) Three-dimensional modeling for modern diagnosis and planning in maxillofacial surgery. Int J Adult Orthod Orthognath Surg 11: 225-233. [Crossref]

8. Halazonetis DJ (2001) Acquisition of 3-dimensional shapes from images. Am J Orthod Dentofacial Orthop 119: 556-560. [Crossref]

9. Kusnoto B, Evans CA (2002) Reliability of a 3D surface laser scanner for orthodontic applications. Am J Orthod Dentofacial Orthop 122: 342-348. [Crossref]

10. Ferrario VF, Sforza C, Schmitz JH, Serrao G, Miani AJ (1998) A three-dimensional computerized mesh diagram analysis and its application in soft tissue facial morphometry. Am J Orthod Dentofacial Orthop 114: 404-413.

11. Oliveira NL, Da Silveira AC, Kusnoto B, Viana G (2004) Three-dimensional assessment of morphologic changes of the maxilla: a comparison of 2 kinds of palatal expanders. Am J Orthod Dentofacial Orthop 126: 354-362. [Crossref]

12. Han SY, Yu HS, Baik HS (2003) The facial soft tissue analysis of the normal occlusion using three-dimensional CT imaging (thesis). Yonsei University; Seoul, Korea.

13. Hajeer MY, Ayoub AF, Millett DT, Bock M, Siebert JP (2002) Three-dimensional imaging in orthognathic surgery: the clinical application of a new method. Int J Adult Orthodon Orthognath Surg 17: 318-330. [Crossref]

14. Ayoub AF, Siebert P, Moos KF, Wray D, Urquhart C, et al. (1998) A vision-based threedimensional capture system for maxillofacial assessment and surgical planning. $\mathrm{Br} J$ Oral Maxillofac Surg 36: 353-357. [Crossref]

15. Lane C, Harrell W Jr (2008) Completing the 3-dimensional picture. Am J Orthod Dentofacial Orthop 133: 612-620. [Crossref]

16. Ackerman JL, Proffit WR (1997) Soft tissue limitations in orthodontics: treatment planning guidelines. Angle Orthod 67: 327-336. [Crossref]

17. Lim HJ, Ko KT, Hwang HS (2008) Esthetic impact of premolar extraction and nonextraction treatments on Korean borderline patients. Am J Orthod Dentofacial Orthop 133: 524-531. [Crossref]

18. Peerlings RH1, Kuijpers-Jagtman AM, Hoeksma JB (1995) A photographic scale to measure facial aesthetics. Eur J Orthod 17: 101-109. [Crossref]

19. Chan EK, Soh J, Petocz P, Darendeliler MA (2008) Esthetic evaluation of AsianChinese profiles from a white perspective. Am J Orthod Dentofacial Orthop 133: 532538. [Crossref]

20. Isiksal E, Hazar S, Akyalcin S (2006) Smile esthetics: perception and comparison of treated and untreated smiles. Am J Orthod Dentofacial Orthop 129: 8-16. [Crossref]

21. Coleman GG, Lindauer SJ, Tüfekci E, Shroff B, Best AM (2007) Influence of chin prominence on esthetic lip profile preferences. Am J Orthod Dentofacial Orthop 132: 36-42. [Crossref]

22. Arpino VJ, Giddon DB, BeGole EA, Evans CA (1998) Presurgical profile preferences of patients and clinicians. Am J Orthod Dentofacial Orthop 114: 631-637. [Crossref]

23. Farrow AL, Zarrinnia K, Azizi K (1993) Bimaxillary protrusion in black Americans--an esthetic evaluation and the treatment considerations. Am J Orthod Dentofacial Orthop 104: 240-250. [Crossref]

24. Shelly AD, Southard TE, Southard KA, Casko JS, Jakobsen JR, et al. (2000) Evaluation of profile esthetic change with mandibular advancement surgery. Am J Orthod Dentofacial Orthop 117: 630-637. [Crossref]

25. Turkkahraman H, Gokalp H (2004) Facial profile preferences among various layers of Turkish population. Angle Orthod 74: 640-647. [Crossref]

26. Kiekens RMA, Maltha JC, Vant-Hof MA, Kuijpers-Jagtman AM (2005) A measuring system for facial aesthetics in Caucasian adolescents: reproducibility and validity. Europ J Orthod 27: 579-584. [Crossref]

27. Cochrane SM, Cunningham SJ, Hunt NP (1999) A comparison of the perception of facial profile by the general public and 3 groups of clinicians. Int $J$ Adult Orthodon Orthognath Surg 14: 291-295. [Crossref]

28. Bell R, Kiyak HA, Joondeph DR, McNeill RW, Wallen TR (1985) Perceptions of facial profile and their influence on the decision to undergo orthognathic surgery. Am J Orthod 88: 323-332. [Crossref]

29. Flores-Mir C, Silva E, Barriga MI, Lagravere MO, Major PW (2004) Lay person's perception of smile aesthetics in dental and facial views. J Orthod 31: 204-209. [Crossref]

30. Giddon DB, Sconzo R, Kinchen JA, Evans CA (1996) Quantitative comparison of computerized discrete and animated profile preferences. Angle Orthod 66: 441-448. [Crossref]

31. Johnston CD, Burden DJ, Stevenson MR (1999) The influence of dental to facial midline discrepancies on dental attractiveness ratings. Eur J Orthod 21: 517-522. [Crossref]

32. Kerr WJ, O’Donnell JM (1990) Panel perception of facial attractiveness. Br J Orthod 17: 299-304. [Crossref]

33. Lu Y, Zhang X (2000) Analysis of facial profile preferences among the Chinese population. Chinese journal of stomatology 35: 224-226. [Crossref]

34. Czarnecki ST, Nanda RS, Currier GF (1993) Perceptions of a balanced facial profile Am J Orthod Dentofacial Orthop 104: 180-187. [Crossref]

35. Soh J, Chew MT, Wong HB (2005) Professional assessment of facial profile attractiveness. Am J Orthod Dentofacial Orthop 128: 201-205. [Crossref]

36. Kerns LL, Silveira AM, Kerns DG, Regennitter FJ (1997) Esthetic preference of the frontal and profile views of the same smile. J Esthet Dent 9: 76-85. [Crossref]

37. Hier LA, Evans CA, BeGole EA, Giddon DB (1999) Comparison of preferences in lip position using computer animated imaging. Angle Orthod 69: 231-238. [Crossref]

38. Tedesco LA, Albino JE, Cunat JJ, Slakter MJ, Waltz KJ (1983) A dental-facial attractiveness scale. Part II. Consistency of perception. Am J Orthod 83: 44-46. [Crossref]

39. Kokich VO Jr, Kiyak HA, Shapiro PA (1999) Comparing the perception of dentists and lay people to altered dental esthetics. J Esthet Dent 11: 311-324. [Crossref]

Copyright: (C2016 Omari AAA. This is an open-access article distributed under the terms of the Creative Commons Attribution License, which permits unrestricted use, distribution, and reproduction in any medium, provided the original author and source are credited. 